\title{
Seed Systems of Traditional African Vegetables in Eastern Africa: A Systematic Review
}

\begin{abstract}
Mathieu A. T. Ayenan ${ }^{1,2 \star}$, Lys Amavi Aglinglo ${ }^{1}$, Herbaud P. F. Zohoungbogbo ${ }^{1}$, Sognigbe N'Danikou ${ }^{3}$, Judith Honfoga ${ }^{1}$, Fekadu F. Dinssa ${ }^{3}$, Peter Hanson ${ }^{1}$ and Victor Afari-Sefa ${ }^{1}$
\end{abstract}

${ }^{1}$ World Vegetable Center, West and Central Africa-Coastal and Humid Regions, Cotonou, Benin, ${ }^{2}$ West African Centre for Crop Improvement, College of Basic and Applied Sciences, University of Ghana, Legon, Ghana, ${ }^{3}$ World Vegetable Center,

Eastern and Southern Africa, Arusha, Tanzania

Traditional African Vegetables (TAV) play an important role in the livelihoods, food and nutritional security of local populations. Access to high-quality seeds of improved varieties is a foundation for increasing crop productivity. TAV seed systems have received little attention. We systematically reviewed the literature to assess the sustainability (seed quality, availability, accessibility, affordability, and profitability of seed businesses) of TAV seed systems in Eastern Africa. The review revealed that the private sector mediated seed system (i.e., formal) offered higher potential for seed quality, and profitability for seed growers. The community-based seed system showed higher potential in ensuring a better access to seeds. The quality of TAV seeds was partially addressed in the studies with a focus on germination percentage and purity, which varied across systems, crops, and geography. While there was a trend of poorer seed quality in the informal system, seed quality in the formal and community-based systems was not necessarily better. The affordability of seed from the various systems (private sector mediated, community based and informal) needs further investigation. Because TAV seed systems are localized and differ significantly among and within countries, tailored interventions are required when promoting a given TAV seed system. We identified inter-regional gaps in TAV seed systems studies, with all the studies concentrated in Eastern Africa, mainly in Tanzania and Kenya. Filling these gaps will require more investment in other regions in sub-Saharan Africa to document existing initiatives or initiate interventions seeking to promote access to high-quality TAV seeds. This review sheds light on existing gaps in research on TAV seed systems to guide future interventions.

Keywords: traditional vegetables, seed quality, orphan crops, neglected and underutilized species, seed system

\section{INTRODUCTION}

Food and nutritional insecurity are a significant concern in developing countries, especially in sub-Saharan Africa, where $57 \%$ of the population cannot afford a healthy diet (FAO, 2020). Food insecurity is aggravated by micronutrient deficiencies, also known as "hidden hunger," a major impediment to social and economic development (Nugent et al., 2020). High malnutrition rates leading to non-communicable diseases such as hypertension, cancer, and obesity are public health challenges (World Health Organization, 2020). In addition, the consumption of fruits and vegetables is far below the recommended amount of $400 \mathrm{~g} /$ capita/day (FAO, 2020). 
Traditional African Vegetables (TAV) are "plant species that are indigenous or naturalized to Africa, well adapted to or selected for local conditions, whose plant parts are used as a vegetable, and whose modes of cultivation, collection, preparation, and consumption are deeply embedded in local cuisine, culture, folklore, and language" (Towns and Shackleton, 2018). TAV [(e.g., amaranth (Amaranthus spp.), African eggplant (Solanum spp.)] are micronutrient-dense and provide nutritional balance to diets among populations whose main staple food is carbohydrate-based (FAO, 2020). The promotion of sustainable production and consumption of TAV is widely recognized as an effective strategy to contribute to diet diversification and to improve nutrition and food security in developing countries (Grubben et al., 2014; Keatinge et al., 2014, 2015; Ojiewo et al., 2015; Ochieng et al., 2018). Many TAV are rich in vitamins and phytochemicals with antibiotic, antioxidants, and anticancer properties and have the potential to reduce the occurrence and severity of non-communicable diseases like hypertension, cancer, and obesity (Yang et al., 2013; Keatinge et al., 2015; Ojiewo et al., 2015). Some TAV are adapted to marginal environments and require little external farm inputs (Ambrose-Oji, 2009; Ebert, 2014); hence, they are an asset for resource-poor farmers and especially women who often lack access to fertile land (Doss et al., 2015; Burke et al., 2018). TAV can contribute to adaptation to climate change by increasing the resilience of local farming systems. Leafy TAV have relatively shorter production cycles (about 30 days for some species) and can be less risk-prone than staple crops, which tend to be more vulnerable to environmental stressors (Ojiewo et al., 2015).

In most African countries, TAV production uses local landraces in low input systems and is intended for household consumption or sale in nearby towns and villages. In some countries, however, the production of certain TAV is shifting into more input-intensive and commercial systems targeting urban areas with high consumer demand (Cernansky, 2015; Ojiewo et al., 2015). Consequently, farmer demand for highquality seeds of improved TAV varieties that meet the quality requirements of urban markets is also increasing. Like other TAV research areas, breeding improved varieties has received little attention. However, a few improved TAV varieties are available that can be promoted and produced by seed producers, including amaranth, African eggplant, African nightshade, jute mallow, kale/Ethiopian mustard, cowpea leaf, spider plant (Dinssa et al., 2016). The available varieties are predominantly open-pollinated (Dinssa et al., 2016). Only one private seed company has developed hybrid African eggplant (Dinssa et al., 2016).

Despite the potential of TAV as a source of income and in ensuring food and nutritional security (Schreinemachers et al., 2018), their production faces several challenges. Lack of a sustainable supply of quality seed is a primary constraint limiting TAV production (Adebooye et al., 2005; Afari-Sefa et al., 2013; Keatinge et al., 2015). Demand for TAV has increased in recent years but, limited availability and accessibility of quality seed of preferred varieties has constrained the ability of farmers to deliver quality products to consumers (Afari-Sefa et al., 2013). The primary seed source of TAV is the informal sector
(Adebooye et al., 2005; Onyango, 2007; Coomes et al., 2015; Croft et al., 2018; Pincus et al., 2018) in which seed quality (genetic purity, germination, phytosanitary status) is highly inconsistent (Keatinge et al., 2015; Pincus et al., 2018). Seed companies are reluctant to invest in orphan crops such as TAV for several reasons, including non-supportive seed legislation, perceived low profit margin, low seed replacement rate, and fragmented seed markets (Minot, 2008), as well as uncertain prospects for development of hybrids of these crops and their demand on the seed market. The need to invest in the TAV seed system is equally underplayed by certification and quality control agencies (Keatinge et al., 2015; Ojiewo et al., 2015). These challenges have prompted increasing interest in developing alternative, farmer participatory TAV seed production and delivery systems. These include private sector mediated seed system (contracted seed production) and community-based seed production systems to make high-quality seed available to farmers (Karanja et al., 2011; Afari-Sefa et al., 2013; Kimenye, 2014; Kansiime and Mastenbroek, 2016). The different smallholder participatory seed production systems raise a question: Do private sector mediated and community-based seed systems ensure better seed quality, availability, accessibility, affordability, and higher profitability than informal seed systems in sub-Saharan Africa? A comparative analysis of the various studies in which TAV seed production systems were tested is necessary to assess their sustainability. Schreinemachers et al. (2021) provide an excellent analysis of the vegetable seed industry and strategies to strengthen the industry as a whole. Kuhlmann et al. (2021) depict how seed laws and regulations affect the private vegetable seed business in SSA. The present systematic review adds to the literature on vegetable seed systems, focusing on TAV and the sustainability of seed production systems in sub-Saharan Africa.

\section{CONCEPT CLARIFICATION}

\section{Seed Systems}

A seed system is a set of activities contributing to variety development and seed production and delivery to farmers. Seed systems are often categorized into three types: formal, semiformal, and informal. A formal seed system is characterized by a well-regulated and organized set of activities, from breeding to delivering certified seeds of known and registered varieties to farmers (Louwaars, 1995). The key distinctive features between formal seed systems and other systems are the registration of seed producers or seed companies and the certification process, which is usually controlled by a public regulatory body. The formal seed system entails various types of arrangements among actors. This review considers contracted seed production or a private sector mediated seed system as part of the formal seed system. A private sector mediated seed system involves individual smallholder seed producers or their cooperatives producing certified seeds under a contract with a private seed company (e.g., Simlaw Seed Limited, East African Seeds, Alpha Seeds Plc) (Karanja et al., 2011; Afari-Sefa et al., 2013; Kimenye, 2014; Kansiime et al., 2021). The informal seed system is outside the control of government agencies, with no external seed quality control. This system includes farmer-saved seed, gifts, barter, and seed purchasing 
from local markets. The semi-formal seed system (termed community-based) is at the interface of formal and informal seed systems. A community-based seed production system involves individual farmers or farmer cooperatives producing Quality Declared Seed (QDS).

\section{Quality Declared Seed}

Quality Declared Seed is a category of seed produced by a registered seed producer subject to quality control and complying with the minimum standards for the crop species concerned (FAO, 2006). The requirements for QDS are less stringent than those of certified seeds while guaranteeing satisfactory seed quality. QDS is an alternative seed quality assurance adapted to contexts where official seed regulatory bodies have limited resources to implement a complete certification scheme (FAO, 2006).

\section{Sustainability of Seed Production}

A sustainable seed production system ensures that "high-quality seeds of a wide range of varieties and crops are produced and fully available in time and affordable to farmers and other stakeholders" (FAO, 2021). A sustainable seed production system encompasses several components: seed quality, availability, accessibility, and profitability of seed businesses. Seed quality refers to genetic (adaptation, varietal purity), physiological (germination, vigor), sanitary (absence of diseases), and physical integrity (percentage of good seeds, free of stones and weed seed) (Almekinders and Louwaars, 1999). Seed availability is the ability to supply sufficient quantities of quality seed to meet the needs of farmers. Seed availability is critical to ensure seed security. Seed accessibility refers to the ability to deliver quality seed in locations within reasonable proximity to farmers when the seed is needed. Seed is affordable when it meets farmers' purchasing power. Profitability is the extent to which a business yields financial gain. Profitability is at the heart of the seed business. In the absence of government subsidies, it determines the viability of the business entity since it influences the decision to participate in seed production.

\section{MATERIALS AND METHODS}

\section{Literature Search and Eligibility Criteria}

We performed a literature search using a combination of the following terms: formal seed system, farmer-led seed enterprises, quality declared seed, community-based seed system, informal seed system, seed quality, seed accessibility, seed affordability, vegetable seed business, traditional vegetable, traditional African vegetable, traditional leafy vegetable, indigenous vegetable, neglected vegetable, underutilized vegetable, vegetable landrace (Supplementary Table 1). We searched in English and French (with translated search strings) without limiting the publication date in various databases, including Web of Science, Scopus, CAB abstract, Google Scholar, and AGRIS. The search in Web of Science, Google Scholar, and Scopus was conducted using Publish or Perish Software with functions "Title words" and "Keywords" (Harzing, 2007). The eligibility criteria are presented in Table 1. Our initial intent in this systematic review was to cover sub-Saharan Africa, but the relevant studies were only carried out in Eastern Africa, hence the focus on this region in the subsequent sections.

\section{Validity Assessment}

Traditional risk of bias tools developed for randomized control trials or observational studies in clinical settings or evaluations of interventions (Moher et al., 2009) cannot directly be applied to the studies on seed production systems. Instead, we used the following four internal and external validity checklist elements identified from West et al. (2002): Description of the study population, sample size justification, application of appropriate statistical, factual outcomes (conclusions supported by data). We also assessed the strength of each paper following Koutsos et al. (2019) ranking conference (papers) as "low"; case and observational studies as "medium"; and experimental studies as "strong."

\section{Data Extraction and Analysis}

We carefully read the 13 papers included in the review and extracted information relevant to our objective using a prepared template. Besides the metadata (authors, title, source of title, keywords, abstract, document type, authors' affiliation), the extracted information was related to the country of studies, type of seed system, seed production system (i.e., private sector mediated, community-based, informal), seed categories (certified, QDS, non-certified), effects of the seed systems on seed quality, availability, accessibility, affordability and profitability, and production and marketing challenges. A data matrix was prepared using these themes as column names and the studies as row names. The extracted data were coded (one when a paper addressed a theme or zero otherwise) and subjected to the computation of frequencies and visualization. Two researchers extracted data from the full texts, and a third researcher crosschecked the extracted data for consistency.

\section{RESULTS}

\section{Literature Search Results}

We exported the search results as CSV files, and after removing duplicates, we obtained 1,742 publications. These publications underwent a screening using the inclusion and exclusion criteria (Table 1). We first screened the titles of the papers and excluded 1,511 papers. The majority of the papers dealt exclusively with the nutritional and economic importance of TAV, ethnobotany and diversity studies, and utilization of TAV. After the first screening, we retained 198 for abstract screening and excluded 165 papers for geographical coverage, publication type (review article), and focus. We read the full texts of 33 papers, and 20 were excluded (Figure 1). Finally, 13 papers met the inclusion criteria and were deemed relevant for the review (Figure 1).

Overall, the studies included in the review had good quality reports, and the population was described. However, eight studies (Onim and Mwaniki, 2008; Karanja et al., 2011; Afari-Sefa et al., 2013; Kimenye, 2014; Kansiime et al., 2016; Rajendran et al., 2016; Mvungi et al., 2020; Ndinya et al., 2020) failed to present the justification of the sample size. Five studies 
TABLE 1 | Inclusion and exclusion criteria of the papers in the review.

\begin{tabular}{|c|c|c|}
\hline Criteria & Inclusion & Exclusion \\
\hline Language & English or French & Other languages \\
\hline Type of research & Primary research & Secondary data \\
\hline Focus and content & $\begin{array}{l}\text { Main focus of the paper is seed systems of TAV Paper explicitly } \\
\text { addresses relationship between seed system and seed quality, } \\
\text { availability, accessibility, affordability and/or profitability }\end{array}$ & $\begin{array}{l}\text { Seed systems of vegetables in general without explicit references to } \\
\text { TAV } \\
\text { Paper does not address relationship between seed system and seed } \\
\text { quality, availability or accessibility or affordability (e.g., Paper on topics } \\
\text { such as mode of pollination/reproduction, varietal preferences, diversity } \\
\text { studies, ethnobotany, economic importance, nutrient contents of TAV) }\end{array}$ \\
\hline Geographical coverage & Areas within sub-Saharan Africa (SSA) & Studies carried out in other regions than SSA \\
\hline
\end{tabular}
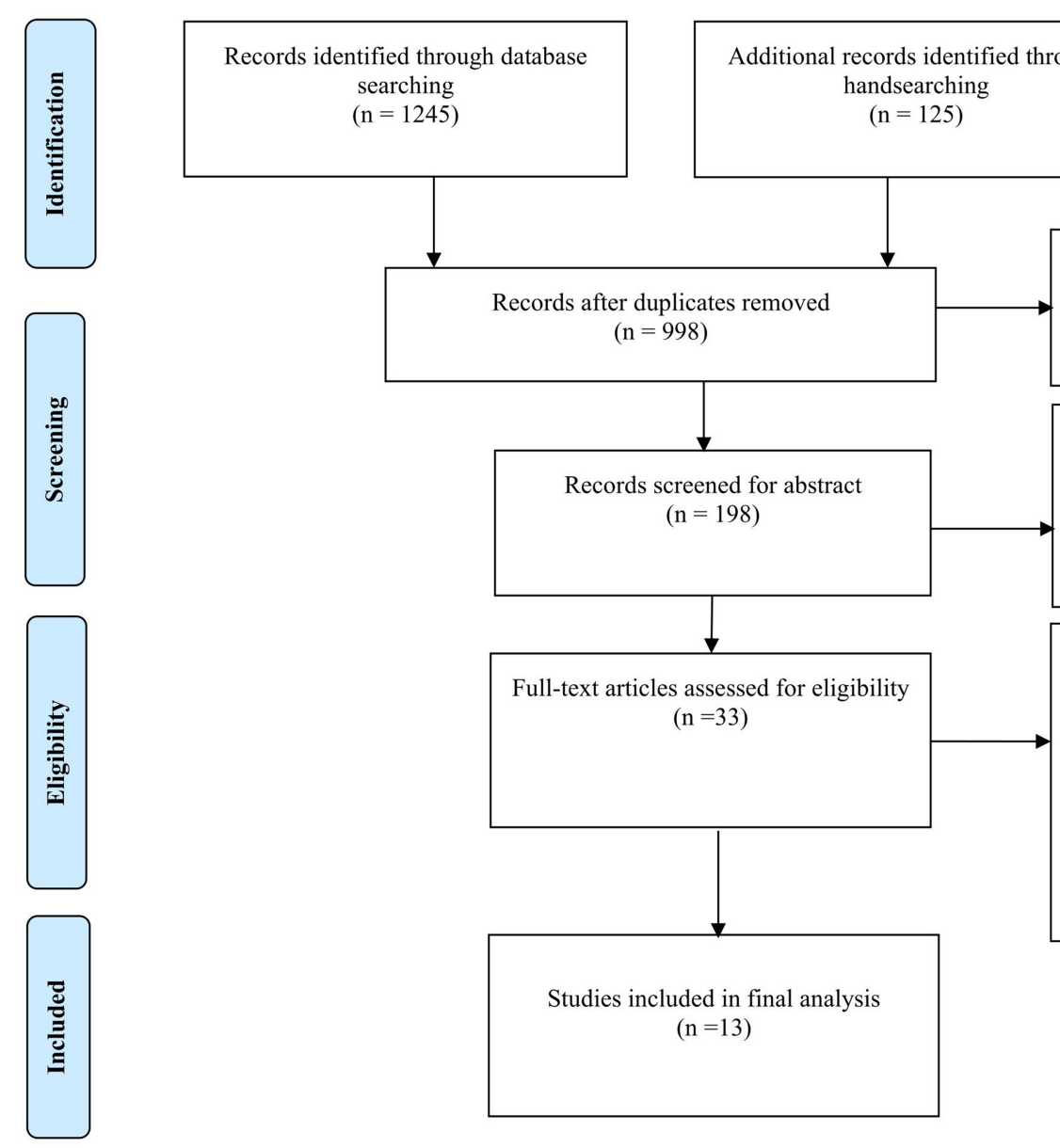

Records excluded after title screening $(\mathrm{n}=800)$

Records excluded $(n=165)$

Focus of the paper, Geographical coverage $(\mathrm{n}=165)$

Full-text articles excluded

Papers focused on seed production and storage

Vegetable seed systems as a whole

Review papers $(\mathrm{n}=20)$

FIGURE 1 | Modified preferred reporting items for systematic reviews and meta-analyses (PRISMA) flow diagram. Adapted from Moher et al. (2009).

(Onim and Mwaniki, 2008; Karanja et al., 2011; Afari-Sefa et al., 2013; Kimenye, 2014; Kansiime et al., 2016) were narrative and did not apply satisfactory analytic techniques. The strength of evidence ranged from low (Onim and Mwaniki, 2008; Karanja et al., 2011) to strong (Croft et al., 2018) (Supplementary Table 2). The remaining studies (Afari-Sefa et al., 2013; Kimenye, 2014; Kansiime et al., 2016, 2018, 2021;
Rajendran et al., 2016; Pincus et al., 2018; Kimaru et al., 2019; Mvungi et al., 2020; Ndinya et al., 2020) had moderate strength of evidence.

The studies on TAV seed systems were all carried out in Eastern Africa, with seven of the studies conducted in Kenya followed by Tanzania (6). The studies were primarily carried out by researchers from the World Vegetable Center Eastern 


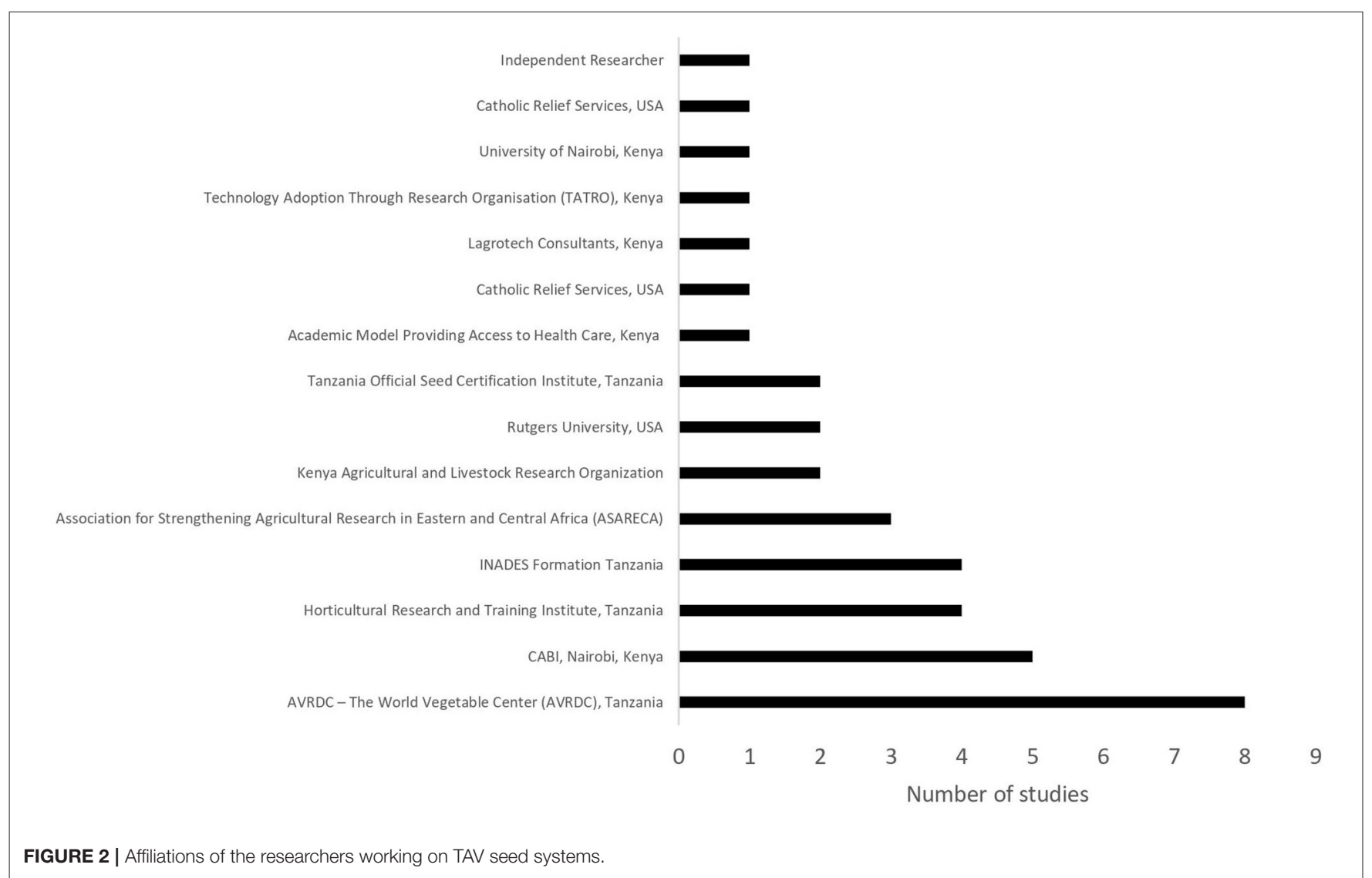

and Southern Africa regional office in Tanzania and the Center for Agriculture and Bioscience International (CABI) in Kenya (Figure 2).

We found nine TAV species (Figure 3 ) covered by the seed systems. African nightshade ranked first in terms of the number of occurrences in the studies (nine studies), followed by amaranth (eight studies), spider plant, Crotalaria, and jute mallow (five studies) (Figure 3). Pictorial representation of TAV reported in this study is given in Figure 3.

\section{TAV Seed Categories Reported in the Studies}

In Tanzania, Quality Declared Seed and certified seed were the predominant seed categories identified across the studies (Onim and Mwaniki, 2008; Karanja et al., 2011; Afari-Sefa et al., 2013; Kimenye, 2014; Kansiime et al., 2016, 2021; Rajendran et al., 2016). Non-certified TAV seed was the most frequent TAV seed category in Kenya (Onim and Mwaniki, 2008; Croft et al., 2018; Pincus et al., 2018; Kimaru et al., 2019).

Seed production and distribution channels were contextdependent and varied widely between and within countries. For instance, Rajendran et al. (2016) reported an exclusive Quality Declared Seed in the Dodoma region of Tanzania, while in Tanga and Morogoro regions, non-certified seed was the only seed category available to farmers.

\section{Sustainability of Seed Production Systems}

We evaluated the sustainability of the different systems using five criteria: quality of seed produced and delivered, seed availability, accessibility, affordability, and the profitability of the seed systems (Reyes and Maredia, 2014; FAO, 2021).

\section{Seed Quality}

Seed quality is of utmost importance for the viability of seed enterprises and food security as a whole. Good quality seed strengthens the trust of farmers in seed producers and encourages them to buy seed. Eleven studies addressed the effects of different systems on components of seed quality. Germination and genetic purity were the most common dimensions addressed (Supplementary Table 3). None of the studies assessed seed sanitary conditions.

Seed quality differs significantly within the same species, depending on the seed systems (private sector mediated, informal, community-based) (Supplementary Table 3). Seed of TAV produced and marketed in informal seed systems was generally of lower quality. In Kenya, Kimaru et al. (2019) found that only certified seed met the International Seed Testing Association (ISTA) standards, while non-certified and farmersaved seed of African nightshade and other seed sold in the markets were of extremely low quality, with purity below $74 \%$. Similarly, germination rates ranging from 33\% for spider plant to $74 \%$ for slender leaf (Crotalaria brevidens) were reported in 


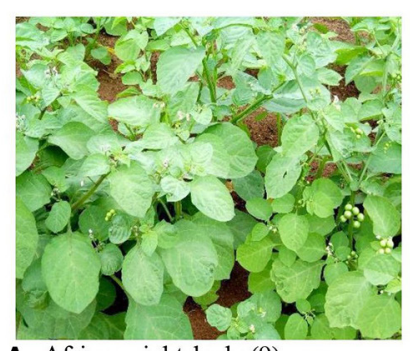

A- African nightshade (9)

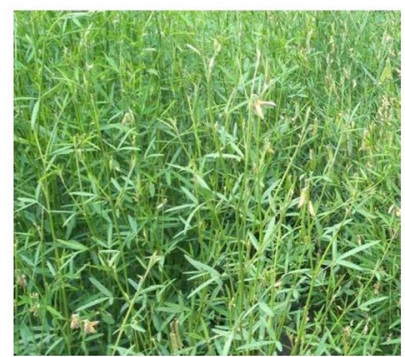

D - Slenderleaf (5)

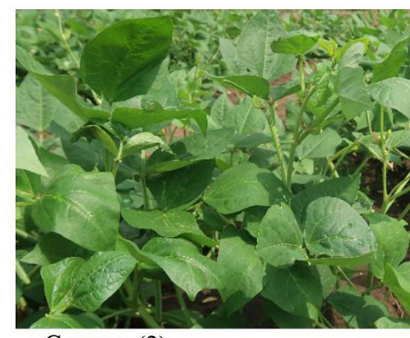

G- Cowpea (2)

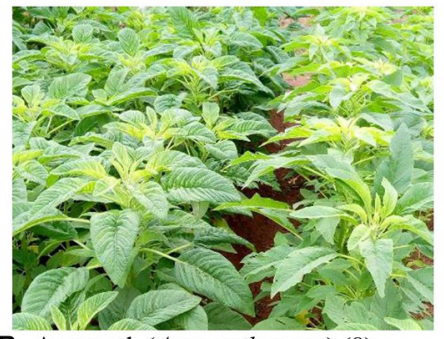

B- Amaranth (Amaranthus spp) (8)
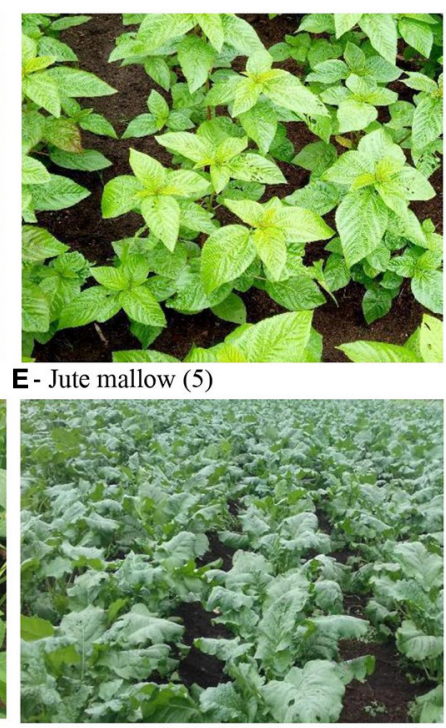

H-African kale (Ethiopian mustard) (2)

Photo Credit: World Vegetable Center

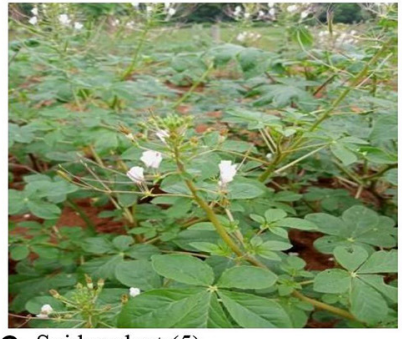

C- Spider plant (5)

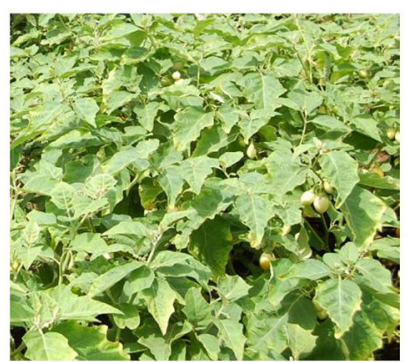

F - African eggplant (3)

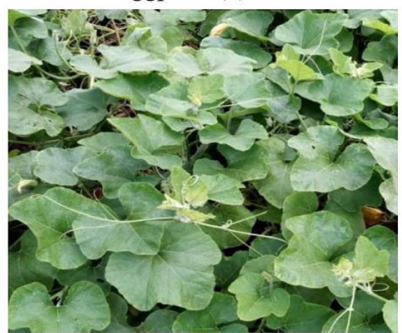

I - Pumpkin (2)

FIGURE 3 | Overview of the TAV species reported in the studies. The values in brackets denote the number of occurrences of the TAV species in the studies included in the review (A) African nightshade (9), (B) Amaranth (Amaranthus spp) (8), (C) Spider plant (5), (D) Slender leaf (5), (E) Jute mallow (5), (F) African eggplant (3), (G) Cowpea (2), (H) African kale (Ethiopian mustard) (2), (I) Pumpkin (2).

Western Kenya in the informal system (Pincus et al., 2018). Poor quality of TAV seeds was also reported from seed companies (Onim and Mwaniki, 2008). Likewise, in Kenya, the germination percentage of amaranth and African nightshade seeds produced by farmers (informal seed system) was about two times higher than seed sourced from seed companies (Croft et al., 2018).

In Tanzania and Kenya, farmers involved in private sector mediated and community-based seed systems improved their seed quality (Karanja et al., 2011; Afari-Sefa et al., 2013; Kimenye, 2014; Kansiime et al., 2016, 2021). This improvement was linked to training received by seed producers, which improved their knowledge and technical know-how (Afari-Sefa et al., 2013; Kimenye, 2014). In Western Kenya, TAV seed producers were trained and received seed for multiplication from the Kenya Agricultural and Livestock Research Organization and its partners (Ndinya et al., 2020). However, the seed produced by those farmers was below the minimum required standards; it was not of better quality in germination percentage and purity than that produced by their non-trained counterparts (Ndinya et al., 2020). The seed produced by the trained farmers was not subjected to any quality assurance. In addition to the training provided to seed producers, a close follow-up during production, seed processing, and the certification process either through certified seed or QDS would be critical to ensure seed quality.

\section{Seed Availability for TAV Production}

Eight studies addressed the effect of the various systems on seed availability. In Tanzania, private sector mediated and community-based seed systems improved the availability of TAV seeds (Karanja et al., 2011; Afari-Sefa et al., 2013; Kimenye, 2014; Kansiime et al., 2016, 2021; Rajendran et al., 2016) (Datasheet 1). For example, from 2009 to 2010 in Kenya, through private sector mediated seed production, there was an increase of the quantity of amaranth seed from $2,134 \mathrm{~kg}$ to $5,918 \mathrm{~kg}$; African nightshade from $3,832 \mathrm{~kg}$ to $27,997 \mathrm{~kg}$; jute mallow from $1,770 \mathrm{~kg}$ to $17,706 \mathrm{~kg}$; and Crotalaria from $6,669 \mathrm{~kg}$ to $24,253 \mathrm{~kg}$ (Kimenye, 2014). In Western Kenya, the informal seed system failed to ensure year-round seed availability for TAV, including amaranth, spider plant, and slender leaf (Pincus et al., 2018). These findings showed that the availability of TAV seed is contextdependent, and private sector mediated and community-based 
seed systems tend to contribute to improved seed availability (Datasheet 1).

\section{Seed Accessibility for TAV Production}

Seed accessibility is an essential component of the sustainability of seed systems and was investigated in eight studies. Private sector mediated and community-based seed systems improved seed accessibility across the countries (Afari-Sefa et al., 2013; Kimenye, 2014; Kansiime et al., 2016) (Datasheet 1). In Uganda, TAV seed dealers in private mediated seed system failed to meet farmers' seed demand (Kansiime et al., 2018). Similarly, farmers experienced challenges accessing TAV seed in the informal system in Kenya (Pincus et al., 2018). In Tanzania, the community-based seed system ensured higher accessibility of TAV seed to farmers because the produced seed was sold within the community, while in the private sector mediated system, the seed was not readily available within the community (Kansiime et al., 2021).

Access to TAV seed was found to be gender-biased in Tanzania, where female-headed households and older farmers were reported to have less access to certified TAV seed compared to their male and younger counterparts, respectively (Rajendran et al., 2016). Identifying the underlying causes for the disparity between male and female and young and adult farmers for access to good quality TAV seed is critical to designing gender-and age-appropriate seed interventions.

\section{Seed Affordability for TAV Production}

Seed affordability has not been addressed widely in the studies included in this review. Only three studies (Onim and Mwaniki, 2008; Kansiime et al., 2016; Croft et al., 2018) assessed the effect of seed systems on seed affordability. Seed from the informal system was reported to be more affordable than certified seed in Kenya (Onim and Mwaniki, 2008; Croft et al., 2018). In Tanzania, Kansiime et al. (2016) reported that seed from the private sector mediated seed and community-based seed systems was affordable. It is worth noting that none of these studies reported figures assessing the extent of seed affordability.

\section{Profitability of TAV Seed Production}

Providing evidence for the profitability of TAV seed could attract investments in the sector. Interestingly, seed system profitability was addressed in six studies (Afari-Sefa et al., 2013; Kimenye, 2014; Rajendran et al., 2016; Kansiime et al., 2018, 2021; Mvungi et al., 2020). In Tanzania, a comparative study between contract seed growers and community-based seed growers revealed that farmers engaged in the latter system had lower input costs and higher returns than contract seed growers (Afari-Sefa et al., 2013). Similarly, Kansiime et al. (2021) reported that farmers in community-based seed production systems earned about US\$ 857 per ha while farmers in contract-based production systems (private sector mediated) earned US\$ 192 from TAV seed. However, these findings were not in line with the report of Mvungi et al. (2020) in Kenya, where contracted TAV seed growers profitably produced seeds of a range of TAV species in contrast with their counterparts in the community-based model, who were only profitable in the production of spider plant seed.
Seed growers in private sector mediated systems had higher yield and selling prices (Mvungi et al., 2020). More specifically, farmers involved in private sector mediated seed system had a higher profit margin ratio (>50\%) than non-contracted farmers who had a negative profit margin for African nightshade and amaranth. An in-depth analysis of the profitability of the seed production system through cost-benefit ratio (CBR) revealed that one dollar invested by contracted seed growers in the production of African nightshade and amaranth seed would yield about US \$ 7.92 and US \$ 6.27, respectively (Mvungi et al., 2020). In the same way, Kimenye (2014) found that farmers in the private sector mediated seed system (Kenya) had higher revenue than community-based (QDS) seed growers (Tanzania). Per cropping season, seed growers involved in private sector mediated seed system earned on average a gross income of US \$ 4,500 producing amaranth, African nightshade, jute mallow, and Crotalaria seed in Kenya. Community-based (QDS) seed growers earned US \$ 300 producing African eggplant, amaranth, and African nightshade seed in Tanzania per cropping season (Kimenye, 2014). Similarly, in Tanzania, income generated per hectare per season from TAV seed was US \$ 907.1, US \$ 892.6, and US \$ 576.5 for the contract seed growers, communitybased seed growers, and seed growers in the informal system, respectively (Rajendran et al., 2016). Seed producers in a private sector mediated system earned a gross margin of US \$ 1325 and US \$ 4500 per ha for Solanum aethiopicum and Amaranthus lividus, respectively (Kansiime et al., 2018). A low profit margin was reported for TAV seed producers in the informal seed system in Kenya (Pincus et al., 2018). For instance, the average annual income from selling TAV seed from the informal seed system ranged from US \$ 15 in Bungoma County to US \$ 28 in Kisumu County in Kenya (Pincus et al., 2018), which was quite low compared to the values reported in Tanzania and Kenya for private sector mediated and community-based seed systems (Afari-Sefa et al., 2013; Kimenye, 2014; Mvungi et al., 2020).

\section{Factors Limiting TAV Seed Production and Marketing}

TAV seed production and marketing were constrained by several biophysical, technical, organizational, and institutional factors. On the production side, pest attacks, low accessibility to improved TAV germplasm, access to land, availability of irrigation water, and lack of technical know-how of seed producers as well as efficient seed extraction methods were major factors limiting TAV seed production (Onim and Mwaniki, 2008; Afari-Sefa et al., 2013; Kansiime et al., 2021). On the market side, difficulty in exploring viable markets and poor differentiation between informal seeds sold in the open market and QDS were major constraints (Table 2). As a result, there was competition between QDS and non-certified farmer-produced seed (Afari-Sefa et al., 2013). Building seed producers' capacity concerning market research, branding, and packaging would improve their market access. Lack of resources (human and technical), understaffing in seed certification agencies, poor or no collaboration between seed sector stakeholders, and nonconducive seed legislation for TAV seed business in many 
TABLE 2 | Factors limiting TAV seed production and marketing.

\begin{tabular}{|c|c|c|}
\hline Constraints of TAV seed production & $\begin{array}{l}\text { Number of studies } \\
\text { reporting the constraint }\end{array}$ & Authors \\
\hline Pest attacks & 3 & $\begin{array}{l}\text { Onim and Mwaniki, 2008; Afari-Sefa et al., } \\
\text { 2013; Kansiime et al., } 2021\end{array}$ \\
\hline Lack of technical know-how on seed production & 3 & $\begin{array}{l}\text { Onim and Mwaniki, 2008; Afari-Sefa et al., } \\
\text { 2013; Kansiime et al., } 2021\end{array}$ \\
\hline Poor quality of farm saved seed & 2 & Onim and Mwaniki, 2008; Kimaru et al., 2019 \\
\hline Difficulty exploring viable markets in QDS & 2 & $\begin{array}{l}\text { Onim and Mwaniki, 2008; Afari-Sefa et al., } \\
2013\end{array}$ \\
\hline Rudimentary seed processing mechanisms & 1 & Kansiime et al., 2018 \\
\hline Poor processing and packaging of seeds from farmers & 1 & Onim and Mwaniki, 2008 \\
\hline Lack of access to foundation seed and quality assurance for QDS growers & 1 & Kansiime et al., 2021 \\
\hline Delay in receiving complementary inputs (Contracted farmers) & 1 & Afari-Sefa et al., 2013 \\
\hline Institutional bottleneck (understaffing in seed certification agencies) & 1 & Afari-Sefa et al., 2013 \\
\hline Challenges in negotiating and adhering to contracts for farmers under contract farming & 1 & Kansiime et al., 2021 \\
\hline Lack of strong collaborative links between seed sector stakeholders & 1 & Afari-Sefa et al., 2013 \\
\hline Fragmented markets for QDS & 1 & Kansiime et al., 2021 \\
\hline Competition between QDS and non-certified farmer-produced seeds & 1 & Afari-Sefa et al., 2013 \\
\hline Insufficient attention given to TAV by private mediated seed sector & 1 & Afari-Sefa et al., 2013 \\
\hline
\end{tabular}

countries are institutional factors to be tackled to foster the production and delivery of high-quality TAV seed to farmers.

\section{DISCUSSION}

\section{Regional Gaps in the Implementation of TAV Seed Systems}

Research on TAV and especially on the development of viable seed systems has received little attention (Afari-Sefa et al., 2013; Dinssa et al., 2015), exemplified by the limited number of studies relevant to be included in this review. Within Eastern Africa, Kenya and Tanzania are predominant in the development of TAV seed systems, for two main reasons:

Project interventions like the Good Seed Initiative funded by Irish Aid through CABI (Kansiime et al., 2016, 2018; Rajendran et al., 2016), and the Multi-Donor Trust Fund (MDTF) to ASARECA (Kimenye, 2014). The majority of the studies stemmed from these projects. This finding shows the vital role of funding in disseminating improved varieties and promoting access to good quality TAV seed. Implementing interventions to improve farmers' access to improved varieties and good quality TAV seed in other regions of the continent is imperative.

There is scarce or no reported information on promoting access to good quality TAV seed in other countries, especially in Western, Central, and Southern Africa where TAV contribute to income generation and nutritional security. More attention is needed to assess, develop, test, and scale promising TAV seed systems, especially in the regions where no study was identified for inclusion in this review.

\section{Sustainability of TAV Seed Systems}

As one can expect for a developing seed system, there is still a pre-dominance of the informal seed system in TAV - an indication of its critical role in providing farmers with TAV seed (Adebooye et al., 2005; Onyango, 2007; Coomes et al., 2015; Croft et al., 2018; Pincus et al., 2018). The TAV seed systems in Eastern Africa are at stage one as per the Douglas scale (1980), a range that describes seed systems. Stage one is characterized by a predominance of farmer-saved seed with low availability of improved varieties. In contrast, stage four depicts a welldeveloped seed sector driven by commercial seed production and marketing. Significant investment in varietal development and creating a conducive policy environment is needed to enhance the availability, accessibility, and affordability of high-quality TAV seed.

The three TAV seed systems have some merits in delivering seed to farmers. The studies we reviewed focused primarily on seed quality (germination and purity), seed availability, and accessibility. However, seed affordability to farmers has received little attention. Seed affordability is a major driver of seed purchase by farmers (Simtowe et al., 2019). We recommend that future studies to assess the viability and sustainability of seed production and marketing systems also address the demand side by evaluating seed affordability for farmers. Such studies should 
investigate the decision-making process of farmers regarding their willingness to invest more into seed purchases.

The informal seed system seems to be more limited in producing and delivering high-quality seed. However, there were instances where seed quality in the formal or community-based system was either poorer or of the same quality as seed from the informal sector (Coomes et al., 2015; Croft et al., 2018). This system deserves special attention (Croft et al., 2018), especially where the formal and the semi-formal seed systems are not operational. Besides potential shortcomings in seed production, processing, and storage from some seed companies, poor seed quality reported from the private sector mediated seed system could be due to the presence of "fake seed" injected into the seed market-a challenge to farmers and seed companies alike. Poorquality seed from a private sector mediated seed system could create distrust and encourage sourcing seed from an informal system. Insufficient technical information is available on methods to optimize seed production (ideal temperatures/rainfall, soil types, isolation distances, crop management practices, avoidance of seed-borne pathogens, seed extraction, seed drying) of many TAV. Such knowledge is often specific for each TAV and should be developed and publicized. The conditions under which TAV are stored are critical for long-term seed health. Actors in TAV seed systems may need to revisit their cultural and postharvest practices, including seed harvesting, threshing or extracting, drying, and storage.

The private sector mediated system with an outgrowing scheme stands out in terms of profitability for seed growers (Kimenye, 2014; Rajendran et al., 2016; Mvungi et al., 2020). In the private sector mediated system, seed growers had access to services, including credit, and improved technologies from seed companies enabled them to realize high profit margins (Mvungi et al., 2020). Those services would likely allow them to improve their productivity, seed quality, and profitability. As long as the producer complies with the contractual arrangement, there is a guaranteed buyer (seed companies), which is not often the case in the other systems (Afari-Sefa et al., 2013). For instance, seed producers engaged in community-based seed systems had difficulty exploring viable markets and selling their seed due to competition from the informal seed sector (AfariSefa et al., 2013), and lacked access to foundation seed (Kansiime et al., 2021). It is worth noting that the private sector-mediated system may be limited in facilitating farmers' access to seed (Kansiime et al., 2021). Private seed companies purchase seed from out-growers but do not necessarily sell it within the community where the seed is produced. As a result, TAV growers in the community may have low access to high-quality seed produced by their fellow farmers. Nevertheless, where a private company is willing to invest in TAV seed production, it may be more sustainable to promote contract-based seed production. However, seed producers must carefully consider the challenges involved in negotiating and complying with the terms of their contracts (Kansiime et al., 2021). Seed quality requirements such as varietal purity, germination, moisture content, etc. must be clear to the seed producers, and seed companies must honor the prices given in contracts so that both parties feel confident, trustful, and secure.
Women play an important role in the production and utilization of TAV. However, current TAV seed systems are not sufficiently gender-responsive. In one example of the informal system, male seed producers earned more than female producers (Pincus et al., 2018). Females experience difficulty in getting contracts with seed companies because of decision-making at the household level and land ownership (Kansiime et al., 2021). Development-oriented interventions in the TAV seed sector should consider gender differences and promote the inclusion of females and youth. Failing to do so would worsen gender inequalities (Pincus et al., 2018).

TAV seed systems are diversified and the predominant systems depend on the crop species and the location. Therefore, one should observe caution in generalizing the information on TAV seed systems. Before developing and implementing seed interventions, a thorough situational analysis should be conducted to achieve the desired impact and avoid disruption in access to high-quality seed (McGuire and Sperling, 2016; Almekinders et al., 2019). Where there is no private seed company interested in TAV seed, promoting a communitybased seed system with Quality Declared Seed as quality assurance, coupled with capacity building for seed growers in production skills, management, and marketing would help ensure sustainable TAV seed production. The choice of a system to be promoted also depends on the objective of the intervention. Interventions seeking to ensure seed availability at the national level could promote the private sector mediated system; when the emphasis is on a given community, it would be preferable to support a community-based seed system with a QDS option if regulations allow.

\section{Diversifying Quality Assurance Options for TAV}

In COMESA, the regional harmonized seed regulations (COMESA, 2014) have not made room for other seed systems except for the formal seed system. This system is characterized by centralized laboratory testing and requires complex logistics and full-time inspectors for field inspections and laboratory testing. These seed quality control services are often understaffed with limited resources for timely field inspection, laboratory testing, and delivery of certificates or tags (Afari-Sefa et al., 2013; Ayenan et al., 2017). Considering the low amounts of seed produced by TAV seed producers, payment for the certification process is almost prohibitive for many local seed companies or seed producer cooperatives. The COVID-19 pandemic has further exposed the low resilience of the system. During the pandemic, lockdowns and other restrictions on movement in many countries have undermined the ability of certification officers to carry out their duties (field inspection, seed sampling, and testing), which could compromise seed quality (Sperling et al., 2020). In addition, there has been a limitation on seed importation from other countries or seed transport within a country, stressing the dire need to foster local seed production. Sperling et al. (2020) rightfully pointed out the need for policy change to redesign the seed system to serve farmers better, reach farmers in remote areas (last mile), and function better under 
normal and stressful conditions. QDS as quality assurance is gaining recognition, and grassroots stakeholders are embracing it, even in challenging seed policy environments. For instance, in Mali, seed regulations do not officially recognize QDS, but initiatives for community-based seed production involve improved and non-improved varieties with unofficial QDS (Diallo and de Boef, 2012; Louwaars et al., 2013). National seed legislation should create enabling conditions for farmers to access quality seed for all crops, especially TAV, because of their importance for improving nutrition and livelihoods.

In addition to QDS, Participatory Guarantee Systems (PGS) used in organic farming for quality assurance could be tested in TAV seed production. "Participatory Guarantee Systems (PGS) are locally focused quality assurance systems. They certify producers based on the active participation of stakeholders and are built on a foundation of trust, social networks, and knowledge exchange." (IFOAM-Organic International, 2008, 2019). This system integrates the simplification of the seed certification process promoted by the QDS scheme and the principles of participation, trust, and empowerment of stakeholders involved in the system.

\section{CONCLUSION}

Studies on TAV seed systems in sub-Saharan Africa are recent and mainly carried out in Kenya and Tanzania. Despite the small number of studies reviewed, we identified interesting trends that could guide future studies and interventions on TAV seed systems. Even though seed quality varied widely within a system, private sector mediated and community-based seed production tends to provide better seed quality. Farmers involved in private sector mediated seed and community-based seed systems had higher profitability than their counterparts in informal systems. The private sector mediated seed system was more profitable to seed growers compared to community-based seed system. Private sector mediated and community-based seed systems improved seed availability. Community-based seed production systems had a better effect on seed accessibility compared to private sector mediated systems. The advantage of the private sector mediated seed system over the community-based seed system lies in the guaranteed market that the former offers to seed growers. The available information from the studies could not discriminate among the three systems based on the affordability of the seed they delivered to farmers. We identified the private sector mediated system as the most sustainable model. However, the promotion of the private sector mediated system requires the existence and willingness of a private seed company to venture

\section{REFERENCES}

Adebooye, O. C., Ajayi, S. A., Baidu-Forson, J. J., and Opabode, J. T. (2005). Seed constraint to cultivation and productivity of African indigenous leaf vegetables. Afr. J. Biotechnol. 4, 1480-1484. doi: 10.5897/AJB

Afari-Sefa, V., Chagomoka, T., Karanja, D. K., Njeru, E., Samali, S., Katunzi, A., et al. (2013). Private contracting vs. community seed production systems: experiences from farmer-led seed into TAV seed production and to contract seed growers. In the light of the regulatory and status of seed sector development in a given intervention area, community-based and informal seed systems could be promoted to improve access to high-quality TAV seeds.

\section{DATA AVAILABILITY STATEMENT}

The original contributions presented in the study are included in the article/Supplementary Material, further inquiries can be directed to the corresponding author.

\section{AUTHOR CONTRIBUTIONS}

MA: conceptualization and literature search. MA, HZ, LA, and SN'D: methodology. MA, HZ, LA, and JH: full text review and writing-original draft preparation. MA, HZ, LA, SN'D, FD, PH, and VA-S: writing-review and editing. PH and VA-S: supervision. All authors have read and approved the version to be published.

\section{FUNDING}

This work received financial support from (i) the European Union and the Netherlands Government through the project Safe Locally Produced Vegetables for West Africa's Market (SAFEVEG), (ii) the German Federal Ministry for Economic Cooperation and Development (BMZ) commissioned by the Deutsche Gesellschaft für Internationale Zusammenarbeit (GIZ) through the Fund International Agricultural Research (FIA), grant number: 81260859 (Choose, Grow, Thrive Project), and (iii) other long-term strategic donors to the World Vegetable Center: Taiwan, UK aid from the UK government, United States Agency for International Development (USAID), Australian Center for International Agricultural Research (ACIAR), Germany, Thailand, Philippines, Korea, and Japan.

\section{ACKNOWLEDGMENTS}

We are grateful to Frejus A. K. Sodedji for his help in conducting the literature search in Web of Science. We appreciate Maureen Mecozzi for her valuable contribution in editing this manuscript.

\section{SUPPLEMENTARY MATERIAL}

The Supplementary Material for this article can be found online at: https://www.frontiersin.org/articles/10.3389/fsufs. 2021.689909/full\#supplementary-material

enterprise development of indigenous vegetables in Tanzania. Acta Hortic. 1007, 671-680. doi: 10.17660/ActaHortic.2013. 1007.78

Almekinders, C., and Louwaars, N. (1999). Farmers' Seed Production: New Approaches and Practices. London: Intermediate Technology Publications, Ltd. doi: 10.3362/9781780442150

Almekinders, C. J. M., Walsh, S., Jacobsen, K. S., Andrade-Piedra, J. L., McEwan, M. A., de Haan, S., et al. (2019). Why interventions in the seed systems of 
roots, tubers and bananas crops do not reach their full potential. Food Secur. 11, 23-42. doi: 10.1007/s12571-018-0874-4

Ambrose-Oji, B. (2009). "Urban food systems and African indigenous vegetables: defining the spaces and places for African indigenous vegetables in urban and peri-urban agriculture," in African Indigenous Vegetables in Urban Agriculture, eds. C. Shackleton, M. Pasquini, and A. Drescher (London: Routledge), 1-33.

Ayenan, M. A. T., Sèwadé, P. L., and Agboton, S. M. (2017). Towards effective soybean seed systems in Benin: current situation and prospects for production and delivery of good quality seed. J. Crop Improv. 31, 1-21. doi: 10.1080/15427528.2017.1304479

Burke, W. J., Li, S., and Banda, D. (2018). Female access to fertile land and other inputs in Zambia: why women get lower yields. Agric. Human Values 35, 761-775. doi: 10.1007/s10460-018-9872-6

Cernansky, R. (2015). The rise of Africa's super vegetables. Nature 522, 146-148. doi: $10.1038 / 522146 a$

COMESA (2014). COMESA Seed Trade Harmonization Regulations 48. Available online at: https:/www.stak.or.ke/wp-content/uploads/2016/08/COMESASeed-Trade-Harmonisation-Regulations-2014.pdf (accessed January 9, 2021).

Coomes, O. T., McGuire, S. J., Garine, E., Caillon, S., McKey, D., Demeulenaere, E., et al. (2015). Farmer seed networks make a limited contribution to agriculture? Four common misconceptions. Food Policy 56, 41-50. doi: 10.1016/j.foodpol.2015.07.008

Croft, M. M., Marshall, M. I., Odendo, M., Ndinya, C., Ondego, N. N., Obura, P., et al. (2018). Formal and informal seed systems in Kenya: supporting indigenous vegetable seed quality. J. Dev. Stud. 54, 758-775. doi: 10.1080/00220388.2017.1308487

Diallo, M. G., and de Boef, W. S. (2012). Mali Seed Sector Assessment. Wageningen: ISSD Briefing Note.

Dinssa, F. F., Hanson, P., Dubois, T., Tenkouano, A., Stoilova, T., Hughes, J. A., et al. (2016). AVRDC-the world vegetable center's womenoriented improvement and development strategy for traditional African vegetables in sub-Saharan Africa. Eur. J. Hortic. Sci. 81, 91-105. doi: 10.17660/eJHS.2016/81.2.3

Dinssa, F. F., Stoilova, T., Nenguwo, N., Aloyce, A., Tenkouano, A., Hanson, P., et al. (2015). Traditional vegetables: improvement and development in subSaharan Africa at AVRDC-the world vegetable center. Acta Hortic. 1102, 21-28. doi: 10.17660/ActaHortic.2015.1102.2

Doss, C., Kovarik, C., Peterman, A., Quisumbing, A., and van den Bold, M. (2015). Gender inequalities in ownership and control of land in Africa: myth and reality. Agri. Econ. 43, 403-434. doi: 10.1111/agec.12171

Douglas, J. E. (1980). Successful Seed Programs. A Planning and Management Guide. Boulder: Westview Press.

Ebert, A. W. (2014). Potential of underutilized traditional vegetables and legume crops to contribute to food and nutritional security, income and more sustainable production systems. Sustain. 6, 319-335. doi: 10.3390/su6010319

FAO (2006). "Quality declared seed system," in Plant Production and Protection Paper 185 (Rome: FAO), 243.

FAO (2021). What are Seed Systems? Available online at: http://www.fao.org/ agriculture/crops/thematic-sitemap/theme/compendium/tools-guidelines/ what-are-seed-systems/en/ (accessed January 9, 2021).

FAO, IFAD, UNICEF, WFP, W. (2020). Food Security and Nutrition in the World. Rome: FAO.

Grubben, G., Klaver, W., Nono-Womdim, R., Everaarts, A., Fondio, L., Nugteren, J., et al. (2014). Vegetables to Combat the Hidden Hunger in Africa. Chron. Horticult. 54, 24-32.

Harzing, A. W. (2007). Publish or Perish. Available online at: https://harzing.com/ resources/publish-or-perish (accessed October 30, 2020).

IFOAM-Organic International (2008). Participatory Guarantee Systems. Case studies from Brazil, India, New Zealand, USA and France, 1-54. Available online at: https://archive.ifoam.bio/sites/default/files/page/files/studies_book_ web.pdf (accessed February 10, 2021).

IFOAM-Organic International (2019). PGS Guidelines. How to develop and manage Participatory Guarantee Systems for organic agriculture. Available online at: https://www.ifoam.bio/sites/default/files/pgs_guidelines_en.pdf (accessed February 10, 2021).

Kansiime, M., Nicodemus, J., Kessy, R. F., Afari-Sefa, V., Marandu, D., Samali, S., et al. (2016). Good seed for quality produce: indigenous vegetables boost farmer incomes and livelihoods in Tanzania. CABI Impact Case Study 17:8. doi: 10.1079/CABICOMM-47-495

Kansiime, M. K., Bundi, M., Nicodemus, J., Ochieng, J., Marandu, D., Njau, S. S., et al. (2021). Assessing sustainability factors of farmer seed production: a case of the good seed initiative project in Tanzania. Agric. Food Secur. 10, 1-10. doi: 10.1186/s40066-021-00289-7

Kansiime, M. K., Karanja, D. K., Alokit, C., and Ochieng, J. (2018). Derived demand for African indigenous vegetable seed: implications for farmer-seed entrepreneurship development. Int. Food Agribus. Manag. Rev. 21, 723-739. doi: 10.22434/IFAMR2017.0095

Kansiime, M. K., and Mastenbroek, A. (2016). Enhancing resilience of farmer seed system to climate-induced stresses: insights from a case study in West Nile region, Uganda. J. Rural Stud. 47, 220-230. doi: 10.1016/j.jrurstud.2016.08.004

Karanja, D., Okoko, N., Kiptarus, E., Okongo, P., Samali, S., Katunzi, A., et al. (2011). "Promoting farmer-led seed enterprises of African indigenous vegetables to boost household incomes and nutrition in Kenya and Tanzania," in Proceedings of the First ASARECA General Assembly (Entebbe), 1-14.

Keatinge, J., Holmer, R., Ebert, A., and Hughes, J. (2014). "Less visible but yet vital for human health: Nutrient-dense indigenous vegetables and their need for urgent promotion in balanced diets," in Proceedings of the Regional Symposium "Promotion of Underutilized Indigenous Food Resources for Food Security and Nutrition in Asia and the Pacific (Khon Kaen).

Keatinge, J. D. H., Wang, J. F., Dinssa, F. F., Ebert, A. W., Hughes, J. D. A., Stoilova, T., et al. (2015). Indigenous vegetables worldwide: their importance and future development. Acta Hortic. 1102, 1-20. doi: 10.17660/ActaHortic.2015.1102.1

Kimaru, S. L., Kilalo, D. C., Muiru, W. M., and Kimenju, J. W. (2019). Evaluation of the quality status of african nightshade seed produced by farmers in Kenya. J. Arid. Agric. 5, 9-16. doi: 10.25081/jaa.2019.v5.5488

Kimenye, L. (2014). Improving access to quality seeds in Africa CABI study brief. Impact. 7, 1-7. doi: 10.1079/CABICOMM-64-57

Koutsos, T. M., Menexes, G. C., and Dordas, C. A. (2019). An efficient framework for conducting systematic literature reviews in agricultural sciences. Sci. Total Environ. 682, 106-117. doi: 10.1016/j.scitotenv.2019.04.354

Kuhlmann, K., Francis, T., and Thomas, I. (2021). Seed Laws and Regulations Affecting the Development of the Private Vegetable Seed Sector in Sub-Saharan Africa. Shanhua; Washington, DC: World Vegetable Center; New Markets Lab.

Louwaars, N. (1995). Policies and strategies for seed system development," in Proceedings of the Integrating Seed Systems for Annual Food Crops, eds M. Sidik, C. E. van Santen, H. Van Amstel, and J. W. T. Bottema (Malang: CGPRT Centre), 5-16.

Louwaars, N. P., de Boef, W. S., and Edeme, J. (2013). Integrated seed sector development in africa: a basis for seed policy and law. J. Crop Improv. 27, 186-214. doi: 10.1080/15427528.2012.751472

McGuire, S., and Sperling, L. (2016). Seed systems smallholder farmers use. Food Secur. 8, 179-195. doi: 10.1007/s12571-015-0528-8

Minot, N. (2008). Promoting a strong seed sector in Sub-Saharan Africa. IFPRI Policy Br. 6:2. Available online at: http://ebrary.ifpri.org/utils/getfile/collection/ p15738coll2/id/12400/filename/12401.pdf (accessed February 10, 2021).

Moher, D., Liberati, A., Tetzlaff, J., and Altman, D. G. (2009). Preferred reporting items for systematic reviews and meta-analyses: the PRISMA statement. BMJ 339, 332-336. doi: 10.1136/bmj.b2535

Mvungi, H., Laizer, A., Lukumay, P., Ochieng, J., Ngoteya, G., Dinssa, F., et al. (2020). Profitability analysis of traditional african vegetable seeds production in Kenya. J. Med. Act. Plants 9:281 doi: 10.7275/08eb-nv32

Ndinya, C., Dinssa, F., Simon, J., Nyabinda, N., Maiyo, N., Weller, S., et al. (2020). Assessment of seed quality of selected African leafy vegetables produced in Western Kenya using informal and semi-formal seed systems. J. Med. Act. Plants 9, 269-280. doi: 10.7275/xnc5-km79

Nugent, R., Levin, C., Hale, J., and Hutchinson, B. (2020). Economic effects of the double burden of malnutrition. Lancet 395, 156-164. doi: 10.1016/S0140-6736(19)32473-0

Ochieng, J., Afari-Sefa, V., Karanja, D., Kessy, R., Rajendran, S., and Samali, S. (2018). How promoting consumption of traditional African vegetables affects household nutrition security in Tanzania. Renew. Agric. Food Syst. 33, 105-115. doi: $10.1017 /$ S1742170516000508

Ojiewo, C., Keatinge, D. J. D. H., Hughes, J., Tenkouano, A., Nair, R., Varshney, R., et al. (2015). The role of vegetables and legumes in assuring food, nutrition, 
and income security for vulnerable groups in Sub-Saharan Africa. World Med. Heal. Policy 7, 187-210. doi: 10.1002/wmh3.148

Onim, M., and Mwaniki, P. (2008). Cataloguing and Evaluation of Available Community/Farmers-based Seed Enterprises on African Indigenous Vegetables (AIVs) in Four EAC Countries. Entebbe, Uganda: Association for Strengthening Agricultural Research in Eastern and Central Africa.

Onyango, M. A. (2007). Seed production and support systems for African leafy vegetables in three Communities in Western Kenya. African J. Food Agric. Nutr. Dev. 7, 1-15.

Pincus, L., Croft, M., Roothaert, R., and Dubois, T. (2018). African indigenous vegetable seed systems in Western Kenya. Econ. Bot. 72, 380-395. doi: 10.1007/s12231-018-9440-4

Rajendran, S., Afari-Sefa, V., Karanja, D. K., Musebe, R., Romney, D., Makaranga, M. A., et al. (2016). Farmer-led seed enterprise initiatives to access certified seed for traditional African vegetables and its effect on incomes in Tanzania. Int. Food Agribus. Manag. Rev. 19, 1-24. doi: 10.22004/ag.econ.230831

Reyes, B., and Maredia, M. K. (2014). Characteristics of a sustainable seed system: application of the principles of sustainability to two models used in Central America," in Proceedings of the Legume Innovation Lab Global Meeting (Athens).

Schreinemachers, P., Howard, J., Turner, M., Groot, S. N., Dubey, B., Mwadzingeni, L., et al. (2021). Africa's evolving vegetable seed sector : status, policy options and lessons from Asia. Food Secur. 13, 511-523. doi: 10.1007/s12571-021-01146-y

Schreinemachers, P., Simmons, E. B., and Wopereis, M. C. S. (2018). Tapping the economic and nutritional power of vegetables. Glob. Food Sec. 16, 36-45. doi: 10.1016/j.gfs.2017.09.005

Simtowe, F., Marenya, P., Amondo, E., Worku, M., Rahut, D. B., and Erenstein, O. (2019). Heterogeneous seed access and information exposure: implications for the adoption of drought-tolerant maize varieties in Uganda. Agric. Food Econ. 7:15. doi: 10.1186/s40100-019-0135-7

Sperling, L., Louwaars, N., de Ponti, O., Smale, M., Baributsa, D., and van Etten, J. (2020). Viewpoint: COVID-19 and seed security response now and beyond. Food Policy 97:102000. doi: 10.1016/j.foodpol.2020. 102000

Towns, A. M., and Shackleton, C. (2018). Traditional, Indigenous, or Leafy? A definition, typology, and way forward for African vegetables. Econ. Bot. 72, 461-477. doi: 10.1007/s12231-019-09448-1

West, S., King, V., Carey, T. S., Lohr, K. N., McKoy, N., Sutton, S. F., et al. (2002). Systems to Rate the Strength of Scientific Evidence. Evidence Report/Technology Assessment No. 47. Rockville, MD: Agency for Healthcare Research and Quality.

World Health Organization (2020). Malnutrition. Available online at: https://www. who.int/news-room/fact-sheets/detail/malnutrition\#: :text=Malnutrition\%2C (accessed February 24, 2021).

Yang, R. Y., Fischer, S., Hanson, P. M., and Keatinge, J. D. H. (2013). Increasing micronutrient availability from food in sub-Saharan Africa with indigenous vegetables. ACS Symp. Ser. 1127, 231-254. doi: 10.1021/bk-2013-1127.ch015

Conflict of Interest: The authors declare that the research was conducted in the absence of any commercial or financial relationships that could be construed as a potential conflict of interest.

Publisher's Note: All claims expressed in this article are solely those of the authors and do not necessarily represent those of their affiliated organizations, or those of the publisher, the editors and the reviewers. Any product that may be evaluated in this article, or claim that may be made by its manufacturer, is not guaranteed or endorsed by the publisher.

Copyright (๑ 2021 Ayenan, Aglinglo, Zohoungbogbo, N’Danikou, Honfoga, Dinssa, Hanson and Afari-Sefa. This is an open-access article distributed under the terms of the Creative Commons Attribution License (CC BY). The use, distribution or reproduction in other forums is permitted, provided the original author(s) and the copyright owner(s) are credited and that the original publication in this journal is cited, in accordance with accepted academic practice. No use, distribution or reproduction is permitted which does not comply with these terms. 